\title{
Construyendo la historiografía peruana: historia e historiadores de la Universidad Nacional Federico Villarreal. Lima (1980-1992)
}

\author{
Poll Gallegos Heredia \\ basadrex@gmail.com \\ Universidad Nacional Federico Villarreal
}

\section{RESUMEN:}

El presente trabajo busca reconstruir los principales elementos iniciales que determinaron la formación de una identidad historiográfica villarrealina entre los historiadores de la Universidad Nacional Federico Villarreal. Dichos elementos fueron la creación de revistas estudiantiles y académicas, la organización de seminarios y eventos, así también la difusión de corrientes historiográficas, que se reflejaron en sus trabajos. Todo como parte del inicio de la Escuela Profesional de Historia durante la década de los años ochenta e inicios de los noventa.

Palabras Clave: Historiografía; Nueva Historia; Historia Social; Marxismo; Universidad Villarreal.

\section{Building the peruvian historiography: history and historians of the National University Federico Villarreal. Lima (1980-1992)}

\begin{abstract}
:
This paper seeks to reconstruct the principal initial elements that determined the formation of a historiographic identity among the historians of the National University Federico Villarreal. These elements were the creation of student and academic journals, the organization of seminars and events, as well as the diffusion of historiographic currents, which were reflected in his works. All as part of the beginning of the Professional School of History during the decade of the eighties and early nineties.

Keywords: Historiography; New History; Social History; Marxism; National University Federico Villarreal.
\end{abstract}




\section{Introducción}

El inicio de la década de los ochenta fue una etapa decisiva para la universidad peruana, la población juvenil entre los 20 y 24 años alcanzaba entonces los 532,624 jóvenes (INEI, 2016). Las aulas universitarias aumentaron en postulantes en 1980 alcanzándose la cifra de 257,220 estudiantes (CVR, 2003). Esta población estudiantil desbordó el alcance y capacidad de las universidades nacionales y parte de las privadas, lo que generó un progresivo deterioro, en las primeras, debido a los bajos presupuestos, la mediocridad de la enseñanza y el incremento del movimiento estudiantil.

Las universidades nacionales se hundieron en una crisis general y las particulares crecieron «en cantidad y calidad de enseñanza», (Degregori, 2013, p. 163), desplazándose a la educación estatal por la privada. Dentro de estos nuevos cambios, el desarrollo historiográfico enfrentó algunos cambios desde la década pasada, así la Nueva Historia, la Teoría de la Dependencia como influencias teóricas y las preferencias por el estudio de la Historia social e Historia económica, continuaron como parte de la agenda de los historiadores. Otros temas como los radicalismos, la violencia y el cambio hacia una nueva etapa por una vía revolucionaria o por las elecciones, influenciaron en parte las agendas de investigación de los historiadores del momento, por ello era complicado encontrar trabajos que se dedicaran a los aspectos culturales o políticos que no estén cerca del enfoque de una «historia desde abajo».

Se conoce siempre que los balances historiográficos suelen ser de investigaciones ya logradas y por lo general fuera del ámbito universitario. Aquí en cambio proponemos estudiar la formación historiográfica inicial desde las aulas universitarias, en específico, la aparición de una «identidad historiográfica» en la Universidad Nacional Federico Villarreal, la cual definimos como el desarrollo de investigaciones (tesis y revistas) elaboradas por estudiantes y egresados con el fin de dar a conocer sus estudios y con ciertas características temáticas que le darían una cierta singularidad frente a la producción historiográfica de la Universidad San Marcos y La Católica.

Son muy pocos los estudios y recuentos sobre el desarrollo historiográfico de las universidades antes mencionadas, contamos con el trabajo de Carlos Contreras (1982) para el caso de la Universidad Católica y el de Alex Loayza (2011) sobre los temas, influencias historiográficas y el entorno académico sanmarquino. Para el caso de la Villarreal contamos con los trabajos de Augusto Lostaunau (2010) y la tesis de maestría de Javier Vega (2015). En el primero notamos un recuento importante sobre las revistas estudiantiles y temáticas entre los años 1980 y 2006, sin embargo existen algunas omisiones que al parecer tienen carácter político. El segundo trabajo, nos ofrece importantes estadísticas y cuadros sobre la evolución de la temática en las tesis y parte del desarrollo institucional de la Escuela Profesional de Historia, no obstante, se notan recortes continuos en los capítulos de la investigación, lo que nos hace perder importante información.

En el presente trabajo hemos pretendido unir dos perspectivas de hacer historia que convivieron y en algunas ocasiones se enfrentaron en el diario acontecer universitario en la Universidad Federico Villarreal o en algunos casos con proyección fuera de la misma como es el caso de la Revista Pasado y Presente. Por ello realizamos entrevistas a diversas promociones pasadas para así intentar reconstruir el contexto, los discursos y las temáticas que le darían forma a la «identidad historiográfica» Villarrealina, para así poder conocer desde el escenario universitario, lugar del inicio de nuestras convicciones temáticas y políticas que formarán parte de nuestro oficio de historiador. 
Construyendo la historiografía peruana: historia e historiadores de la Universidad Nacional Federico Villarreal. Lima (1980-1992)

\section{La convivencia necesaria: EI inicio de la Escuela Profesional de Historia en la Universidad Villarreal (1980-1992)}

\section{Construir una Nueva Escuela (1980-1986)}

Hasta 1980 no existía, dentro de la Facultad de Ciencias Sociales y Administrativas, una Escuela que se dedicase a la formación de historiadores en la Universidad. Como un antecedente a la formación del Programa de Historia, antes solo la Facultad de Educación y Humanidades impartía una especialidad de docencia en Historia. Sin embargo es hasta finales de los años 70, donde se gesta el nacimiento del Programa académico de Historia en Villarreal, que surge como parte del desdoblamiento de los programas académicos de Administración y Ciencias Sociales, el 17 de mayo de 1979 y fue su principal impulsor el Dr. Gustavo Vergara Arias.

Algunos docentes del programa según el testimonio citado por Javier Vega (2015), tenían una motivación de formar una historia más popular cercana a la teoría histórica del aprismo:

Recordemos que Villarreal nace como filial de la Universidad Comunal del Centro del Perú, una Universidad para los hijos de los comuneros y queríamos una historia para el pueblo, creíamos que el relativismo histórico era un marco teórico apropiado para conocer mejor la historia del Perú (p. 96).

Aquel espacio era quizás el que pretendía establecer una influencia del Apra en las ciencias sociales, con una Escuela propia surgida en sus canteras, pues dicho partido «no había ejercido dicho rol que se restringía a la política nacional» (Remy 1992, 285). Esta motivación no tuvo resultado pues no se creó ninguna escuela en base a esas perspectivas teóricas.

El Programa presentó en un inicio, dificultades que no se regularizaron hasta cerca de tres años después, debido a los problemas con la Comisión Nacional Interuniversitaria (CONAI) que finalmente concluyó en 1984, al aprobarse la Ley universitaria, el Estatuto de la Universidad y el reconocimiento al Programa de Historia.

Este desbalance administrativo fue notorio y se constituyó en un problema en el desarrollo del año académico y por consiguiente afectó el desarrollo de los ciclos y semestres. El profesor Luis Lázaro Llantoy, docente durante esos años, recuerda sobre el asunto:

Yo entré en el 81 y la Universidad tenía un rezago académico...por paros y huelgas...de tal manera que yo estaba en 1980 II, segundo semestre y era Abril de 1981, es decir, se estaba empezando recién. (L. Lázaro, comunicación personal, 23 de abril de 2014).

El ambiente político general de la Facultad de Ciencias Sociales, durante la primera etapa del Programa de Historia estaba dentro de las disputas y alianzas de grupos pertenecientes al Partido Aprista Peruano (PAP). En la Villarreal a diferencia de la Universidad San Marcos, fueron los grupos apristas los que mantenían cierto control político en la década de los 80 e inicio de los años 90. Ellos mantenían desde la década pasada, una pugna constante que reflejaba un panorama de inestabilidad permanente. Algunos de estos grupos fueron: «La Alianza Revolucionaria Estudiantil (ARE)-Nueva Izquierda, el Comando Universitario Aprista (CUA), Izquierda Democrática Estudiantil (IDE) y Vanguardia Aprista». (Agüero, 2009)

Estas divisiones y alianzas eran reflejo de la crisis del Partido Aprista en 1981. Sin embargo este ambiente empezaría a cambiar en el transcurrir de los años, debido a que comenzó a pluralizarse con el ingreso de estudiantes que militaban en sectores de izquierda y otros que se alejaban de pertenecer a alguna ideología política. 
El clima inicial en la Villarreal variaba en tiempos de turbulencia y estabilidad de acuerdo al movimiento de algunos grupos políticos, pese a que otras universidades nacionales enfrentaban continuas paralizaciones de clases y toma de locales, sumado a la difusión de un «marxismo de manual», que persistía en algunos cursos de la currícula. El caso de San Marcos «no produjo un número considerable de tesis o una escuela historiográfica, pese a los esfuerzos de algunos docentes como Miguel Maticorena y Carlos Lazo, Waldemar Espinoza, etc.» (Loayza, 2011, pp. 14-15).

Si vemos una comparación entre los años 1980 y 1992 solo se sustentaron dos tesis en San Marcos, una de licenciatura y otra de doctorado: Luis Cajavilca «Las haciendas jesuitas de Pisco (Siglos, XVII-XVIII)». 77 h. Tesis de Licenciatura. (1982) y Mario Cárdenas titulada «La población aborigen del Valle de Lima en el s. XVI.» Tesis Doctoral (1987). (Pérez, 2013, pp.1-18).

La Universidad Católica, en cambio, producía una cantidad de tesis considerable, que desde los años setenta impulsaban los estudios en Historia social e Historia económica y la Etnohistoria, «que proporcionó herramientas para el estudio de las fuentes en beneficio de los jóvenes historiadores» (Contreras, 1982, p. 117) y representó otro espacio de difusión académica durante la década de los 80, no solo dentro de la Historia, sino de todas las Humanidades. Su Archivo Histórico y Biblioteca especializada se convirtieron en una fuente necesaria, acogiendo también en su momento a varios historiadores de distintas instituciones.

Las realidades de las universidades mencionadas, serían importantes para entender el ingreso de población estudiantil al Programa de Historia de la Universidad Villarreal, que llegaría a convertirse en una salida de estudios para los que se retiraban de San Marcos y que no podían mantenerse económicamente en la Universidad Católica. Un caso de ellos fue el historiador Augusto Ruiz Zevallos alumno ingresante a la especialidad de Historia en la Villarreal en 1981, que recuerda:

Decidí migrar a la Universidad Federico Villarreal. Alberto Flores Galindo, luego de una conferencia que dictó en San Marcos, conversando de manera informal con varios alumnos que le exponíamos nuestro descontento, mencionó que en Villarreal había una escuela que recién se había creado por iniciativa de Germán Peralta, quien (esto lo supe después) había coincidido con Flores y Burga en Francia y venía con ideas frescas de la última generación de Annales y con el suficiente criterio para programar un plan curricular más conveniente. (A. Ruiz, comunicación personal, 11 de octubre de 2012).

De la misma forma, Carlos Aguirre, compañero de Augusto Ruiz, luego de seguir Ingeniería Química en la Universidad Nacional de Ingeniería (UNI), postuló al Programa de Historia de la Facultad de Ciencias Sociales de la UNFV. Según Aguirre:

La Villarreal acababa de abrir su escuela de Historia dirigida entonces por Germán Peralta, que hacía poco había vuelto de Francia. Yo conocía a Germán a través de vínculos de amistad forjados cuando yo militaba en el Partido Aprista a fines de los años 70. Por tanto, decidí postular al programa de Historia de la Universidad Villarreal y pude así concretar mi anhelo de seguir una carrera en el área de Ciencias Sociales (San Martín, 2009, p. 168).

Como ya hemos mencionado, muchos alumnos provenían de una experiencia no necesariamente cercana al Partido Aprista, Augusto Ruiz provenía de una experiencia en el Centro Federado de Letras, por la Especialidad de Comunicación en la Universidad San Marcos, como parte de la Izquierda Unida (IU), Carlos Aguirre, provenía de la Juventud aprista y había 
pertenecido al grupo de estudios Ateneo Claridad, parte de la Izquierda Aprista en 1980, hasta alejarse tiempo después, solo por dar algunos ejemplos sobre el alumnado de entonces.

La Currícula del Programa, intentó reflejar una variada formación para el historiador, con visión panorámica desde el ámbito historiográfico, la investigación y la administración en archivos. La aparición de cursos como Técnicas bibliográficas, Epistemología, como parte de la formación de historiador, para el aspecto teórico: Filosofía de la Historia, Materialismo Histórico, Antropología Cultural y Sociología de la Cultura y otros para el desempeño laboral como Planificación, organización y administración archivística histórica, Administración en Archivología Nacional y Didáctica de la Historia.

Sin embargo el panorama en el ámbito docente no era muy alentador, debido a la presencia de muchos educadores y pocos especialistas, algunos docentes llegaron desde la Universidad San Marcos y otros desde la Universidad Católica y su tiempo de permanencia en algunos casos fue fugaz. Pocos docentes tenían una preparación adecuada para una actualización necesaria sobre dichos temas de la currícula, en muchos casos no se preparaban las clases y se improvisaban con manuales. Un número reducido de docentes dejó lo necesario, un espacio pequeño, que incluso pese a los problemas internos, convirtieron al Mimeógrafo como herramienta, para la difusión de materiales.

Entre los docentes podemos resaltar a Sócrates Villar Córdova, Francisco Iriarte Brenner, Germán Peralta, Ada Arrieta Álvarez, Laura Gutiérrez Arbulú, Jorge Mariano Cáceres-Olazo Monroy, entre otros. Villar había realizado investigaciones en torno al Tahuantinsuyo, como la institución del Yanaconaje y era un docente retirado de San Marcos, Iriarte era un arqueólogo de profesión conocido por sus investigaciones en Puruchuco. Peralta Rivera había realizado estudios de doctorado en Francia con una tesis sobre los mecanismos del comercio negrero en los siglos XVI y XVII, Arrieta y Gutiérrez se habían dedicado al trabajo paleográfico y archivístico con importante experiencia y Cáceres-Olazo, antropólogo realizó investigaciones sobre movimientos sociales y el folklore. Esta diversidad no impulsó la creación de grupos de estudios, ni publicaciones o escuelas historiográficas alrededor de estos docentes.

Lo que si apareció fue un cierto impulso en sus alumnos para conseguir enlaces con otros centros de investigación, que sería fructífero a largo plazo. Rosaura Andazábal, integrante de la primera promoción en 1980, recuerda el apoyo de uno de sus docentes y el vínculo que le ayudó acercarse a otras instituciones, así:

Por ese tiempo, iniciaba yo mis prácticas en el Archivo Histórico Riva Agüero (de la PUCP), con la historiadora y archivera Ada Arrieta Álvarez, quien era mi maestra de paleografía en la UNFV y me había adiestrado en la lectura y descripción documental del siglo XVI en adelante, lo que me valió para que Ilder Mendieta me recomendara con el doctor Macera, con quien finalmente me entrevisté en setiembre de 1985, en el Archivo Histórico de la Beneficencia Pública de Lima (AHBPL). Allí pude ver los libros de cuentas, margesies de rentas y censos, enfermería, entre varios otros documentos, correspondientes a los hospitales fundados en la Lima colonial, como el Real de San Andrés (españoles), Real de Santa Ana (indios), San Bartolomé (negros), San Lázaro (Leprosos), De la Caridad (españolas), etc. (R. Andazabal comunicación personal, 15 de abril de 2014).

El otro complemento académico fue el contacto entre bases, compartiéndose lecturas no revisadas, generándose así otros vínculos frente a los problemas que se afrontaban, Augusto Ruiz sobre el valor de buscar otras salidas teóricas: 
El ser autodidacta para compensar las falencias de la universidad fue muy importante, debido a que entonces no había mayores influencias, salvo esta de la escuela de Annales y la que nosotros podiamos agenciarnos con nuestra actitud estudiantil. El marxismo occidental, la sociología histórica o la historiografía británica, fueron cosecha propia (A. Ruiz, comunicación personal, 11 de octubre de 2012).

Por otra parte Carlos Flores, alumno ingresante en 1983, hoy docente asociado de la Escuela Profesional de Historia reafirma este nexo importante entre estudiantes de años superiores y la circulación de lecturas teóricas:

Por aquel entonces, era el intercambio, el rotar los libros lo más importante, la fotocopia aún no era tan difundida, fue la amistad con Augusto Ruiz que me dio los referentes de autores como Hobsbawm y Thompson. (C. Flores, comunicación personal, 03 de octubre de 2012).

Como notamos, los estudiantes buscaron en gran parte otras salidas a los problemas académicos que afrontaba la universidad y en algunos docentes, los nexos importantes para acceder a otras instituciones de investigación y la circulación de lecturas entre promociones fueron un aporte necesario en la formación.

Hasta el año 1985, con la normalización y reconocimiento del Programa Académico de Historia, muchos docentes que habían permanecido desde la fundación del mismo, se retiraron, «muchas veces por cuestiones económicas y otros por el acoso de los grupos políticos que intentaban intervenir en sus resultados académicos y sus clases». (R. Andazabal comunicación personal, 15 de abril de 2014).

En el contexto político nacional, el triunfo de un gobierno aprista y la acentuación de las disputas políticas, llevaron ese año a que la universidad afrontase una etapa muy crítica, que llegó a repartirse el control del gobierno entre dos autoridades (dos rectores). Algunos egresados ya comenzaban a realizar sus primeras publicaciones y ver proyectos propios fuera de la Universidad. Hasta ese momento no se habían producido tesis, debido a que la primera promoción había culminado recientemente y la segunda estaba en vísperas de finalizar. Es recién en 1986 donde aparece la primera Memoria de Bachiller, titulada El Manicomio y la Ciudad, sustentada por Augusto Ruiz Zevallos.

\section{Crear una nueva identidad: La Escuela Profesional de Historia y los historiadores de la Villarreal (1986-1992):}

En 1985, con el ascenso de un primer gobierno aprista, la Universidad Villarreal, pasaría una de las crisis más profundas de su joven historia, cuando en febrero de ese año, se anularon las elecciones de Rector que habían dado por ganador a Gustavo Vergara Arias y como reacción provocó que una turba de estudiantes irrumpiera en el local de votación, rechazando la elección e imponiendo a Enrique Sifuentes como verdadero Rector (S/a, 1985 p. 5). Dos rectores que simbolizaban una creciente inestabilidad y grupos de estudiantes como el Comando Universitario Aprista (CUA-ARE) y la otra facción llamada también Alianza Estudiantil Revolucionaria (ARE), se enfrentaban continuamente por sus candidatos (S/a, 1985 p. 6).

Tal situación generó la intervención del entonces presidente Alan García como mediador y «se suspendieron las rentas a la universidad tiempo después» (S/a, 1985 p. 2). Ese problema finalmente llegó a su solución al renunciar ambos rectores, convocándose a nuevas elecciones, eso evitó «la intervención de la Asamblea Nacional de Rectores (ANR) o el posible receso ordenado 
por el parlamento» (S/a, 1985 p. 2) , sin embargo, se suspendió el examen de admisión de ese año, postergándose al siguiente. Este conflicto fue exclusivamente entre grupos apristas, que como mencionamos habían copado muchas de las instituciones que formaban la universidad.

La Universidad Villarreal era percibida como patrimonio indiscutible del Partido Aprista, poniéndose en duda hasta la veracidad de los concursos de admisión y de la disputa de las ansiadas vacantes. El «ser aprista» podía asegurarte, según esta percepción, un acceso rápido sin necesidad de postular. El testimonio de Javier Vega, ingresante en 1986, explica lo mencionado anteriormente, sino también el factor geográfico que identificaba a los nacidos en Trujillo, como cercanos al aprismo, pues se consideraba a esta ciudad como parte del llamado "sólido norte», bastión electoral de dicho partido político:

Como para matar el tiempo comentábamos y repetíamos los rumores que circulaban con gran profusión: los apristas están que hacen ingresar a su gente, ya todo está arreglado, si no eres aprista no ingresas, etc. Otros conversábamos sobre el lugar de donde procedíamos, a mi por venir de Trujillo, me identificaron como aprista, tú sí ingresas -me decían- (Vega, 2001, p. 117).

La información sobre la especialidad de Historia era prácticamente nula y una incógnita, no había más percepción de la que ya existía, sin embargo, los grupos políticos apristas se hacían presentes a los «cachimbos», Vega recuerda:

Por supuesto que de su Escuela de Historia sabía solamente que existía; una decisión más intuitiva que racional orientaba mis esperanzas. Ya en ella, habia más información del Comando Universitario Aprista (CUA) y de la Alianza Revolucionaria Estudiantil (ARE) y también de los diferentes grupos de izquierda apodados «rábanos», que bajaban de los ciclos más avanzados; de la historia de la Escuela, nada. (Vega, 2001, p. 118).

En contraste con la realidad universitaria, algunos egresados los que continuaron con la carrera de historiador, iniciaron sus estudios de maestría o para trabajar en algunos centros de investigación. Uno de esos centros fue el Seminario de Historia Rural Andina (SHRA), impulsado por Pablo Macera que acogió varios proyectos donde participaron estudiantes y egresados villarrealinos como: Ilder Mendieta, Luz Peralta, Rosaura Andazabal, entre otros muchos más que terminaron en publicaciones y ponencias en congresos. Precisamente es en el Seminario, «donde aparece la primera publicación de un egresado villarrealino: Hospitales en Lima Colonial, siglos XVII.XIX, publicado por Ilder Mendieta hacia 1990». (L. Peralta, comunicación personal, 22 de noviembre de 2016). El Seminario se constituyó así en un semillero de investigación y de contacto permanente con estudiantes de otras universidades.

Los intereses de los egresados villarrealinos en la elección de una maestría en Historia recayó en la oferta ofrecida por la Universidad Católica, sus docentes tenían un cierto acceso a otras lecturas y perspectivas que en la Villarreal no se daban, la Universidad San Marcos no estuvo entre los intereses de los egresados, por lo menos durante esa década, debido a los problemas que atravesaba. En la mayoría de los casos, los estudios de postgrado fueron financiados por las oportunidades que ofrecía el CONCYTEC. Esta ayuda permitió que egresados como Carlos Aguirre puedan concretar sus estudios en la Universidad Católica en 1987. La experiencia sería importante por la presencia de importantes historiadores del momento que le darían otra visión que se complementaría con la recibida en la Villarreal:

Tuve la fortuna de tomar clases con historiadores como Franklin Pease, Scarlett O'Phelan, Alberto Flores Galindo, Heraclio Bonilla y Christine Hunefeldt. Entonces mi paso por la 
Católica representó una apertura a nuevos temas, nuevas influencias, nuevos profesores, nuevos amigos y es el paso que concreta mis años en la Villarreal con lo que vino después. (San Martín, 2009, p. 173).

Dentro de los egresados villarrealinos que accedieron a la maestría en la Universidad Católica encontramos a los integrantes de la primera promoción como: Rosaura Andazabal, María Elena Dávalos Castañeda, Ilder Mendieta Ocampo, Jorge Montero Saco, Martin Muñoz Zuloaga y Matilde Torres Ruiz. Por parte de la segunda promoción (1981) encontramos a: Carlos Aguirre, Augusto Ruiz Zevallos y Luz Peralta Apaza. (R. Andazabal comunicación personal, 15 de abril de 2014).

El acceso a una maestría, permitió a muchos egresados, perfeccionar y ampliar los conocimientos que habían recibido en la universidad, así como cubrir los vacíos dejados por algunos cursos y continuar sus estudios en el camino de la investigación. En la Universidad Villarreal, las cosas tomaban otro rumbo, los ingresantes al Programa académico de Historia aumentaron de sobremanera, presentándose una sobrepoblación en las bases de 1986, 1987 y 1988, que fueron repartidos en dos turnos y que «sumaban alrededor de más de 200 alumnos matriculados, evidentemente la infraestructura y la enseñanza impartida en la Universidad había colapsado» (A. Lostaunau, comunicación personal, 14 de abril de 2014).

Estas últimas promociones antes de la intervención de la Comisión Reorganizadora (CORE) en 1992, estaban en su mayoría interesadas en la historia social, con presencia de lecturas de tinte marxista y en algunos casos compartían una militancia política que los enfrentaba a los grupos apristas de ese momento. Otro grupo de estudiantes en cambio, no asumirían estos ideales e incursionaron en otras formas de hacer historia, más cercanos a la historiografía francesa, había pues, un grupo heterogéneo que convivía en el mismo espacio.

El Giro lingüístico había empezado a hacer su incursión en la Historiografía y algunos de estos estudiantes se mostraron contrarios y permanecieron dentro de una historia «que rendía culto a la objetividad, que era equivalente a lo científico, donde las estructuras y los cambios de ellas eran parte de la naturaleza del discurso histórico» (Glave, 1996, p. 7). Aquellos estudiantes leían autores como Pierre Vilar, Maurice Godelier, Jean Chesnaux y Eric Hobsbawm. Los manuales fueron usados en menor medida entre los que podemos resaltar fueron: El Materialismo Histórico de F.V. Konstantinov y Los conceptos elementales del materialismo histórico de Martha Harnecker. Esta generación de estudiantes «recibió la última etapa de la influencia de la llamada Nueva Historia, pero indirectamente, es decir como lectores, bajo otros signos metodológicos» (Quiroz, 1999, p. 109).

Los planes curriculares de 1980, 1983 y 1986, consideraron como curso al Materialismo dialéctico histórico, el cual para aquellos estudiantes era considerado como parte de una introducción a la Historia, es decir «como herramienta teórica que le permitía al historiador un trabajo de rigor científico» (Lostaunau, 1993, p. 8), por eso el interés del estudio de "la metodología del marxismo era importante incluso para el análisis de la sociedad" (O. Rojas, comunicación personal, 29 de octubre de 2012).

Ese análisis era tan importante como las leyes que regían a la historia, el historiador era un intelectual comprometido, es decir, su trabajo «mostraba la manera en que cambiaban las cosas y también como él, podía influir en el cambio de nuestro país». (Glave, 1999, p. 355). Esta idea de buscar cambios, estaba latente en los estudiantes y ejercieron presión sobre diversos problemas de la facultad, en este caso la demanda de la poca investigación producida y la solicitud de 
presencia de más especialistas que pudiesen desplazar a los educadores que allí enseñaban. Las solicitudes se convirtieron en publicaciones estudiantiles y además se creó un evento que pueda convertirse en una tradición propia de la especialidad de Historia e identifique el desarrollo de la investigación histórica en la Universidad Villarreal, hasta ese momento.

Surgieron así los Viernes de Historia para incentivar «una complementación a los conocimientos adquiridos a través de las aulas, las lecturas o las investigaciones» (Lostaunau, 1989, p. 2), y cubrir vacíos temáticos. Este evento empezó a generar un mayor intercambio académico con los estudiantes, los egresados y los historiadores de otras universidades. Al estar conectado, buscaba también reforzar la identidad historiográfica en la Villarreal, traducida en investigaciones diversas. Las temáticas iniciales de la primera reunión fueron:

las funciones que cumple el historiador en nuestra sociedad, el Historiador y sus trabajos en los archivos, importancia del compromiso del historiador y la realidad social, proyección de la Escuela de Historia dentro de nuestra universidad y de nuestro país (Lostaunau, $1989 b$, p. 2).

En la siguiente sesión se conversó sobre «el Perú prehispánico» y sobre algunos temas de historia social, aquí participaron; Jorge Mariano Cáceres-Olazo Monroy con «Las formaciones económicas Sociales pre-incas» y Sócrates Villar Córdova con «El Régimen del Trabajo en el Incario»». (Lostaunau, 1989 c, p.1). Estas temáticas iniciales muestran parte de la mentalidad, en lo referente al lugar del historiador para con su sociedad y su aporte a la misma, vigente como ya explicamos anteriormente.

A inicios de los años 90, la crisis económica afectó severamente a las universidades nacionales, el gobierno de Alberto Fujimori aplicó las medidas económicas neoliberales para intentar reflotar la economía y después de hacer frente al conflicto interno que ya desbordaba a gran parte del país. El Congreso promulgó el decreto legislativo $\mathrm{N}^{0} 739$ donde se eliminaba la Memoria o tesina para obtener el grado de Bachiller de manera automática y también la segunda opción para obtener la licenciatura a través de una monografía por servicios profesionales a la universidad por tres años. En 1992, poco después del Autogolpe del 5 de abril, la Universidad Villarreal fue intervenida junto a las otras universidades públicas, e ingresó una Comisión Reorganizadora (CORE) para dirigir a la Universidad.

Se suprimieron varias libertades y se expulsaron a varios docentes, los grupos políticos desaparecieron poco a poco. Las revistas estudiantiles dejaron de aparecer y las nuevas generaciones de estudiantes que ingresaban se alejaban casi por completo del papel del historiador como intelectual comprometido, además los nuevos planes de estudio empezaron a reflejar los cambios de la historiografía, la crisis de los paradigmas y el llamado giro lingüístico. Había llegado así: la Novísima Historia.

Los cursos que mostraban teoría o ideología como Materialismo Histórico Dialéctico y Relativismo Histórico solo aparecieron hasta el Plan Curricular de 1992. Para ese entonces, algunos egresados culminaron sus estudios de maestría e intentaron abrirse paso fuera del país. Carlos Aguirre sustentó su tesis Conflicto, resistencia y adaptación: los esclavos de Lima y la desintegración de la esclavitud, 1821-1854. Lima (1990) y pudo después partir hacia los Estados Unidos. Augusto Ruiz sustentó sobre La Multitud y el mercado de trabajo. Modernización y conflicto en Lima de 1890 a 1920 en 1993 y se incorporó al cuerpo de profesores de la especialidad de Historia de la Villarreal, otros continuaron trabajando en sus centros de investigación como 
Rosaura Andazabal y Luz Peralta, así como otros se decidieron por la enseñanza en escuelas y el trabajo en archivos.

En la Universidad, algunos egresados establecieron un nuevo evento más amplio para lograr una tradición que no solo los identificara, sino a los alumnos y a toda la Escuela de Historia, así en 1992, se realizó el Primer encuentro de alumnos y ex alumnos de Historia-UNAVI, donde se debatieron en tres mesas sobre; «el carácter científico de la Historia, el Quinto Centenario del Descubrimiento de América y el carácter de la formación del historiador de la Universidad Villarreal» (A. Lostaunau, comunicación personal, 14 de abril de 2014).

Este evento partió, como mencionamos, desde alumnos egresados, pero se convirtió en su momento en parte de la Escuela Profesional de Historia de la Villarreal, ambas reuniones continuaron por tres a cuatro años más ininterrumpidamente hasta que en el año 1995, apareció el Coloquio Interdisciplinario de Investigaciones Históricas, que seguía las experiencias del Coloquio de Historia de la Universidad Católica y los intentos del Coloquio de Lima y de San Marcos.

Fue este Coloquio y la comisión organizadora (COESCO), que se convirtió en institucional y desplazó al anterior evento, con ello terminaría la primera etapa de formación de una identidad historiográfica y ahora quedaría la consolidación de la misma en plena intervención.

\section{III.Una nueva identidad historiográfica}

En esta parte realizaremos un acercamiento de las principales publicaciones (revistas) impulsadas tanto por alumnos y egresados de la Escuela Profesional de Historia de la Villarreal y de las tesis sustentadas hasta el año 1992.

\section{III.1 Las revistas, una imagen de la historiografía en la Villarreal:}

Los problemas no detuvieron a los alumnos que buscaron crear espacios de reflexión y difusión académica. El primer intento de alumnos egresados de la Villarreal por generar un espacio no solo para sus investigaciones sino proyectar una idea renovadora, fue la revista Pasado y Presente: revista para una historia alternativa, una idea gestada por alumnos que seguían la maestría en Historia de la Universidad Católica y agrupó a jóvenes historiadores de esa universidad y extranjeros. El Comité editorial estuvo formado por Augusto Ruiz Zevallos, Juan Luis Orrego, Carlos Aguirre, Juan Dejo y Lizardo Seiner y como editor figuraba Hilario Enríquez. Para el segundo número figuraban también: Charles Walker y como colaboradores el historiador español Josep Fontana, el lingüista Marcos Martos entre otros.

La revista se enfocó más desde el lado interdisciplinario y gran parte de las temáticas estaban entre los temas vigentes del momento, la del primer número fue sobre «el Racismo» y el siguiente sobre «Rebelión y Revolución en la Historia». Parte de los miembros del comité editorial se sentía identificado como historiador comprometido con su sociedad y en este caso con un proyecto: el Socialismo. En su primer editorial decían que:

El compromiso con el presente implica, por supuesto una opción política: nadie puede escapar a esta verdad evidente. Lo decimos con claridad desde ahora: nos ubicamos dentro de la ancha corriente que apuesta por un futuro socialista para nuestro país (Editorial, 1988, p. 1). 
El ascenso de la izquierda peruana se basaba en el aporte de diferentes matices, con una historia de disputas en los años 60 entre pro soviéticos y pro chinos y con referencias teóricas, que podían ubicarse en el maoísmo, el trotskismo y autores como Poulantzas, Althusser, Lukacs, entre otros más. «La llamada "Nueva Izquierda", no mantenía más proyecto que el idealismo que ya tenía, abundantes en intelectuales, carecía de una producción teórica propia» (Flores Galindo, 1996, p. 120), que le permitiera consolidarse en el espacio político e ideológico.

Este escenario en la búsqueda de nuevas perspectivas, para el caso de los editores de Pasado y Presente, era más bien sumar fuerzas para identificar ideales por el cambio y con miras a un proyecto socialista, aunque desde una vertiente más académica y más abierta en busca de una pluralidad.

Proclamamos desde ahora nuestra apertura democrática a pensamientos diversos y adoptamos el pluralismo como herramienta para desbrozar el camino que conduce a la verdad. Por ello nuestras páginas están abiertas a la colaboración de distintos matices políticos e intelectuales (Editorial, 1988. p. 1.).

Los mismos editores formaron el Instituto Pasado y Presente que realizó algunas publicaciones, hasta por efecto de la crisis y por decisión de los mismos, decidieron tomar caminos separados. Pasado y Presente si bien no fue una publicación de estudiantes, sí fue una iniciativa de egresados villarrealinos que logró ubicar una publicación en un espacio importante.

En la Universidad Villarreal, la situación era caótica como hemos explicado, por ello, algunos alumnos se juntaron en grupos de estudio para sortear estas deficiencias y elevar el nivel académico, así aparecieron dentro de la base 86, el Círculo de estudios «José Carlos Mariátegui» y en otra el «Círculo de estudios Emilio Choy», por citar unos ejemplos.

En esa coyuntura a finales de los años 80 son a través de estos círculos de estudio, «aparecen las revistas estudiantiles que mostraban su rechazo al nivel académico que se ofrecía» (Lostaunau, 2011, p. 35), por eso su labor editorial fue principalmente de divulgación de textos y de servir como una pequeña ventana para los aventurados y en algunos casos, avances de investigación de los estudiantes. Las ediciones fueron rústicas, el mimeógrafo o Stencil fue el instrumento para estas publicaciones.

Estas revistas iniciaron hacia el año 1990 y fueron: Ensayo, Revista de Historia y Actualidad, editado por el Grupo editorial Ensayo, Yawar Llaqta: Alcances para una Nueva Historia, hecha por el grupo del mismo nombre, Tinkuy: Revista para una historia reivindicativa, por el Círculo de estudios «Emilio Choy» y Problemas de Historia, publicada por la Promoción 88 II, llamada «Sócrates Villar Córdova».

Augusto Lostaunau recuerda el origen de sus inquietudes y lo que significó para formar parte de un comité editorial y editar una revista:

Algunos de sus miembros tenían una primera participación en el movimiento estudiantil al formar parte del Grupo editorial Ensayo, otros ya habiamos formado parte de los Círculos de estudios José Carlos Mariátegui y Rumi Maqui donde nos limitamos a debatir lecturas pero, recién con «Ensayo» que dimos el salto y producir aportes para una mejor comprensión de la ciencia histórica y una interpretación objetiva de la verdad histórica (Lostaunau, 2011b, p. 3).

Los materiales publicados en estas revistas van desde la recopilación de reconocidos autores, que los editores consideraban más cercanos a sus intereses académicos y la publicación 
de avances y bosquejos de investigación de los alumnos, es decir, una ventana para incentivar las publicaciones, que la especialidad padecía, incluso se publicaron manuales y compilaciones, siendo el docente que más apoyó en su momento estas ediciones, Jorge Mariano Cáceres-Olazo Monroy, catedrático de cursos como Movimientos Sociales e Historia Social, activo coeditor de muchas de estas revistas en las que colaboraba.

La vida de estas publicaciones fue efímera y coyuntural, aparecen en el momento de transición, cuando la Historiografía ya había virado hacia la Historia Cultural y la Nueva Historia Política, por lo que hacer una historia centrándose únicamente en las rebeliones, la resistencia y los movimientos sociales frente al orden establecido, dentro de estructuras o ideologías, fue dejado de lado para pasar a los discursos, las mentalidades y el lenguaje. La intervención de la Universidad Villarreal en 1992, cerró una etapa, donde publicaciones que mostraban ideología o posición política abierta, eran censuradas, con ello, la Universidad entró en otro ciclo, que llevaría incluso a la separación de Historia y la recién creada Arqueología de la Facultad de Ciencias Sociales para crear una nueva institución, la Facultad de Humanidades en 1997.

\section{III.2 Las primeras tesis del Programa Académico de Historia de la Villarreal}

Dentro de todos estos vínculos, la producción misma fue somera pero concisa dentro de la misma universidad. Entre 1980 y 1992, se sustentaron cuatro tesis de licenciatura y una memoria de bachiller. Las temáticas abordadas son principalmente de Historia Social, no existe además una línea tradicional de investigación y se exploran nuevos temas, cada autor utiliza diferentes herramientas y el conocimiento de autores que van desde la historia social británica (Edward P. Thompson), algunos conceptos de Michel Foucault y la Escuela de los Annales. Las dos primeras sustentaciones de investigaciones se titularon, El manicomio y la ciudad (1986) y la multitud y las subsistencias. Lima 1900-1919, la primera memoria de bachiller y la siguiente, tesis de licenciatura, ambas sustentadas por Augusto Ruiz Zevallos.

En el primer trabajo, Augusto Ruiz, se acerca al tema de la psiquiatría y la enfermedad mental a través del estudio del aumento de la población de los manicomios, ocupado por alcohólicos, mezclados con artesanos, jornaleros, agricultores frente a los que ostentaban profesiones liberales; Estudiantes, empleados o comerciantes. Según el autor aquello no ocurrió como deterioro del nivel de vida de las clases populares, sino por parte de la realidad económica y las categorías manejadas por los psiquiatras de la época, es decir un aspecto coyuntural por etapas, entre finales de la era del guano, la crisis económica y la reactivación de la economía a fines del siglo XIX. Es decir, la modernización de Lima afectó a varios gremios de trabajos tradicionales, lo que expuso a muchos desocupados que en algunos de los casos, se recluyeron en el alcoholismo. Este resultado fue controlado por las elites a través de la psiquiatría.

Ruiz Zevallos utiliza para interiorizar las características y conceptos de la medicina mental en el Perú, los testimonios y memorias publicadas por José Casimiro Ulloa y Manuel Muñiz en La Gaceta Médica de Lima y La Crónica Médica. Asimismo, con aquellas fuentes, describe la mentalidad de la modernización médica psiquiátrica, así como de las patologías a tratar.

Para verificar la población y los tipos de personas que habitaban en el manicomio, revisó las memorias de la Sociedad de Beneficencia Pública de Lima, donde encontró el número de pacientes enviados desde provincias a la capital, considerado alarmante por los médicos, debido a la cantidad de enfermos. 
Sin embargo, el autor va más allá, pues consulta los indicadores económicos, donde descarta que haya existido una crisis continua, pues nota una recuperación del nivel de vida a finales del siglo XIX, post guerra con Chile. Aunque las profesiones comunes como aguadores, veleros son afectadas por la modernización de Lima, también los estragos de una crisis, antes y después de la Guerra, tocó a los artesanos, que formaban un número considerable en el Manicomio de Lima.

Concluye en el epílogo que las cuestiones que los psiquiatras de la época daban a la sobrepoblación del Manicomio se debían más a la realidad socioeconómica del momento que al aumento del alcoholismo en la Ciudad. No obstante, el autor llama la atención que ambos factores van separados y que también la realidad socioeconómica, tuvo sus momentos de crisis, al negar una crisis prolongada para los trabajadores y que esta se reflejara en el sanatorio mental.

En el segundo trabajo, Ruiz se acerca al concepto de «economía moral» de Edward P. Thompson, esta idea engloba los comportamientos no basados en la teoría económica, sino en patrones culturales y sociales. Es decir parte de un consenso entre el pueblo, los comerciantes y el gobierno, donde se fija el precio y se vende el producto asequible, así como se garantiza el abastecimiento de los mercados. Cualquier actitud en contra, buscando el afán de lucro personal o el desabastecimiento generando hambre o crisis, generaba una revuelta o motín de subsistencias, para recuperar dicho acuerdo. Esta idea siempre estaba presente, no solo «en momentos de disturbios». (Thompson, 1984, pp. 62-134).

Ruiz decidió estudiar las expresiones de protesta popular en Lima de inicios del siglo XX, y además, «la alimentación y se centra en ver la revuelta de mayo de 1919, encabezada por el Comité Pro abaratamiento de las subsistencias» (Ruiz, 1988, p. 2). La tradición es un elemento importante que el autor toma en cuenta para la comprensión de las revueltas. Para evaluar el nivel de vida en Lima, estudia el consumo de carne en la población y de los otros productos alimenticios que formaban parte importante en la dieta popular. Nota además la influencia de la situación económica, lo que hace subir los precios, como el de la carne, debido a que era importante en su dieta diaria, este desnivel en los costos, desencadenarán los motines por las subsistencias en 1919. Aquellas asonadas, concluye, fueron un medio importante a través del cual los sectores populares urbanos supieron defender su nivel de vida.

Carlos Aguirre sustentó la tesis de licenciatura titulada Disciplina, castigo y control social, Lima 1821-1868. Aquí Aguirre estudia los diferentes mecanismos de control que ejercen las clases dominantes frente a los que no siguen las leyes y normas impuestas, aquí el autor usa eficazmente las visiones sobre el castigo corporal y las formas punitivas estudiada por Foucault, aunque priorizando los cambios sociales que producen los mecanismos punitivos, la herencia colonial de la república, sus cambios y la modernización a mediados del siglo XIX. El autor ensaya el término de «Cultura plebeya», que representa las costumbres, aficiones, tradiciones que mantiene la plebe limeña durante un período en específico y que se enfrenta formalmente a toda imposición que pretende suprimir aquellas características.

Algunas de estas costumbres eran parte de los juegos, fiestas y las formas de trabajo, que eran confundidas por el Estado como actos de ocio y vagancia, sin embargo la plebe podía modificar los intentos de control social, al prevalecer su «resistencia» a estas imposiciones. No obstante, el real sentido sería «una manera de adaptación a una mejor manera de afrontar sus gastos y aficiones, que la disciplina social y laboral eran elementos con los cuales, la plebe no se identificaba» (Aguirre, 1990, p. 43), aquí se acerca al mismo concepto trabajado por Hans Medick. 
Además Aguirre, relaciona mucho el tema a la perspectiva contemporánea; los constantes usos de la violencia y la represión del delito que afectaban al Perú:

A mediados de los años 80 atravesábamos una época en que las cárceles peruanas vivían una crisis aguda, con la proliferación de motines, algunos de ellos muy sangrientos, y me parecía que era un tema que reclamaba una atención por parte de los historiadores. Ya habia publicado Michel Foucault su famoso libro sobre el nacimiento de la prisión, y otros autores como E.P Thompson o Douglas Hay habian estado trabajando sobre temas relacionados con la ley, el ejercicio del castigo y la criminalidad. Esta confluencia de factores o elementos historiográficos y preocupaciones relacionadas con la situación concreta del país me convencieron de que el tema merecía un tratamiento de carácter histórico. (San Martin, 2009, pp.170-171).

También tenemos a María Dávalos con su tesis: Análisis histórico de la tenencia de tierras de Maranga a la Magdalena (S.XVI-XX). Ella realiza un estudio de larga duración sobre el proceso de tenencia de Maranga hasta su nacimiento como distrito de Lima. La pertenencia de esas tierras por el curaca Taulichusco y las actividades que allí se realizaban, seguidamente la ocupación colonial de esos terrenos, donde se implantó no solo el repartimiento y se modificó el espacio hasta que en el siglo XIX, «este lugar se transforma de un sistema rural a un sistema urbano» (Dávalos, 1989, p. 127). Con ello prueba la importancia de estas tierras para las diferentes autoridades que pasaron a gobernarlas y ordenarlas.

Para reconstruir su trabajo, la autora consultó un gran número de crónicas, que describen el contexto y las características del Señorío a la llegada de los españoles. Seguidamente, describe las tierras del nuevo propietario Nicolás de Ribera «El Viejo» basándose en la documentación encontrada en el Archivo General de la Nación, Biblioteca Nacional del Perú, Archivo Arzobispal, Archivo de la Iglesia de Nuestra Señora de María Magdalena, entre muchos otros.

En su mayoría, los documentos notariales le permitieron rastrear a los diferentes propietarios y herencias, desde la fundación de la reducción de indios de Magdalena, hasta la era republicana, lo cual constituye un seguimiento muy importante. Las escribanías permitieron una mejor descripción de dichas tierras y los límites y utilidad a través del tiempo.

No es además una historia del traspaso de las propiedades o predios a través del tiempo, es también una historia de evolución del Valle del Rímac, una Historia Local, en específico del espacio conocido como La Magdalena, donde no solo encontraremos a los dueños, sino también a pobladores, trabajadores y autoridades, que habitan en dicho lugar.

Asimismo, nos explica el origen de la Casa de los Virreyes (Hoy Museo de Antropología, Arqueología e Historia del Perú) y de lugares característicos de la llamada "Magdalena Vieja", desde finales de la colonia al Estado republicano. El surgimiento del distrito de Magdalena y la aparición del distrito de Pueblo Libre, son producto del desarrollo de dicho espacio que muestra una reutilización y permanencia en dicha localidad a través del tiempo.

Por último tenemos, la tesis de Carlos Villanueva titulada: Una aproximación a la historia de la producción artística de Lima en el siglo XVII", aquí el autor muestra que las imágenes reflejaban «la concepción ideológica absolutista y cortesana de la metrópoli, evocaba parte de su condición social, que se basaba en la posesión de la tierra y parte de sus aficiones» (Villanueva, 1991, p 252), así como de la élite limeña, que buscaba imponerla a las clases subalternas, por ellos los talleres y los artistas que trabajaban en ellas, no podían escapar a dicha influencia. 
Sin embargo también, los subalternos se veían reflejados en dichas imágenes, un espacio libre que mostraba su origen y su vida cotidiana, ambos grupos entraban en interacción en las creaciones de estos maestros. La tesis reproduce varias imágenes y láminas de artistas del siglo XVII.

Para ello revisó documentación del Archivo Arzobispal de Lima (AAL), como partida de bautizos y expedientes matrimoniales, en base a estas fuentes, en uno de los capítulos, el autor describe las peripecias de estos importantes artistas y sus talleres como parte de la vida cotidiana del artista limeño del siglo XVII. Los trabajos con protocolos notariales son muy notables y minuciosos. Concluye que las expresiones artísticas de la Lima del siglo XVII, fueron interclasistas, que evocaban condiciones sociales y tradiciones, además representa parte de la contradicción de la sociedad colonial y reta a la historiografía que llama "conservadora» por ignorar la función social de los objetos artísticos más allá de lo meramente decorativo.

Como podemos observar, en esta primera etapa, las tesis se desarrollaron principalmente dentro del periodo republicano y en menor medida con el Virreinato. La Historia social es parte importante de las investigaciones, aunque no haya conseguido formarse una escuela historiográfica.

\section{Conclusiones}

La reciente etapa de formación de la historiografía en la Universidad Villarreal, fue parte de construir y ampliar los lineamientos de la naciente Escuela de Historia, aunque principalmente de generar espacios de difusión académica que ella carecía. Las revistas impulsadas por egresados y estudiantes, así como los eventos organizados, generaron una visión de la escuela y la apertura de nuevos espacios para los historiadores de la Villarreal. Las tesis sustentadas, abrieron nuevos caminos para la historiografía y avanzaron por temas como la locura, el castigo, la larga duración y el significado de las imágenes en el arte. Todos estos elementos reforzarían el surgimiento de una identidad historiográfica Villarrealina que podía estar abierta a las nuevas corrientes históricas y que podía «convivir», con dos tipos de hacer historia que solían anteponerse. La pluralidad y la diversidad, son pues características de esta nueva identidad.

\section{Fuentes Primarias}

S/a (04 de Octubre de 1985).Informe especial. Expreso, 4-5.

S/a (08 de Octubre de 1985).Informe especial. Expreso, p. 6

S/a (11 de Octubre de 1985). Informe especial. Expreso, p. 2

\section{Fuentes secundarias}

\section{Bibliografía}

Agüero, T. (2009). Testimonio sincrónico: A propósito de las partes que desde abajo y en silencio revolucionan las cosas y el mundo. Recuperado el 03 de Abril de 2015. http://www.vanguardiaaprista.com/090640especialtitoa.html.

Aguirre, C. (1990) Disciplina, castigo y mecanismos punitivos. : Estudios sobre conductas sociales y mecanismos punitivos. Lima, 1821-1868. (Tesis de Licenciatura), Universidad Nacional Federico Villarreal, Lima.

Comisión de la Verdad y la Reconciliación (2003) Las organizaciones sociales: Las Universidades. Recuperado el 15 de Marzo de 2015. http://www.cverdad.org.pe/ifinal/index.php. 
Contreras. C. (1983) Nuevas tendencias en la historiografía peruana. Las tesis de la Pontificia Universidad Católica del Perú. 1975-1982. Histórica, Vol. II, (1): 111-122.

Dávalos, M. (1989) Análisis histórico de la tenencia de tierras de Maranga a la Magdalena (S.XVI-XX). (Tesis de Licenciatura), Universidad Nacional Federico Villarreal, Lima.

Instituto Nacional de Estadística e Informática (2016) Censos poblacionales 1981, VIII de población y III de Vivienda. Recuperado el 17 de Marzo de 2016. http://censos.inei.gob.pe/censos1981/redatam/.

Glave, L. (1996) Imágenes del tiempo: De historia e historiadores en el Perú contemporáneo. Lima: Documento de Trabajo No79, Instituto de Estudios Peruanos.

(1999) La memoria y el futuro en la historia del Perú. Fort, M. y Lemlij, M. (Ed.). En el Umbral del Milenio, Vol. I, (pp. 355-369).Lima: Prom Perú, SIDEA.

Loayza, A. (2011) Introducción, Notas sobre la Historiografía en San Marcos después de la "Nueva Historia". En León, D, Loayza, A y Garfias, M. (Eds.) Trabajos de Historia. Religión, cultura y política en el Perú, siglos $X V I I-X X$. (13-33). Lima: Fondo editorial UNMSM.

Lostaunau, A. (1989) Los Viernes de Historia. Discurso Inaugural del "Primer seminario de Historia del Perú: Pre inca/Inca, Local Central, Aula 10. Viernes, 8 de Setiembre de 1989”. Lima: Inédito.

(1989 b) Crónica de Nuestro Primer Viernes de Historia, Promoción 87 Turno Tarde. Lima, Inédito, Texto mecanografiado.

(1989 c) “Dos Viernes de Historia Villarrealina”, Promoción 87, Turno Tarde, Lima, Inédito, Texto mecanografiado.

(1993) El pensamiento crítico debe ejercerse sobre nosotros: sobre las lecturas y las motivaciones de los historiadores durante la década de los 80’S. Lima: Inédito.

(2011a) Dos Generaciones de Historiadores Villarrealinos. A propósito del trigésimo aniversario de la Escuela Profesional de Historia de la UNFV (1980-2010). Síntesis Social (3), Lima: 220-240.

(2011 b) Comentario a los aportes de Jorge Cáceres-Olazo Monroy en Ensayo: Revista de Historia y Actualidad (1990-1992). Lima: Texto Leído en el VI Encuentro de Alumnos y Ex Alumnos de Historia UNFV. Homenaje al Dr. Jorge Mariano Adrian Catulo Cáceres Olazo Monroy, 14, 15 y 16 de Diciembre del 2011.

Pérez. J. (2013) Tesis de Historia presentadas en la Universidad Nacional Mayor de San Marcos (1910-2010)". Nueva Corónica (1), Lima: 1-18.

Quiroz, F. (1999) La Historiografía joven peruana 1987-1995. Diálogos en la Historia, (1), Lima: 109-128.

Ruiz, A. (2011) Alberto Flores Galindo, marco sociopolítico, fronteras teóricas y proyecto político. Histórica (35), Lima: $12-51$.

(1988) La Multitud y las subsistencias 1900-1919. (Tesis de Licenciatura), Universidad Nacional Federico Villarreal, Lima.

San Martín, J. (2009). Esclavitud, Prisión e Historia Social. Entrevista a Carlos Aguirre. Tiempos, (4), 167-180.

Vega, J. (2001) La Escuela Profesional de Historia de la Universidad Nacional Federico Villarreal. Documento de Trabajo. Historias: Revista de Historia y Sociedad, (2), Lima: 117-119.

(2015) La producción historiográfica de la Escuela Profesional de Historia de la Universidad Nacional Federico Villarreal, 1980-2013 (Tesis de Maestro en Docencia universitaria), Universidad Nacional Federico Villarreal, Lima.

Villanueva, C. (1991) Una aproximación a la historia de la producción artística de Lima en el siglo XVII. (Tesis de Licenciatura), Universidad Nacional Federico Villarreal, Lima.

Presentado: 21 junio 2017

Aceptado: 28 enero 2018

Publicado online: 11 julio 2018 